\title{
INTERCÂMBIOS ACADÊMICOS INTERNACIONAIS: BOLSAS CAPES, CNPQ E FAPESP
}

\author{
DÉBORA MAZZA
}

Professora do Departamento de Ciências Sociais Aplicadas

à Educação da Faculdade Educação da Universidade Estadual de Campinas

dmazza@unicamp.br

\begin{abstract}
RESUMO
Este artigo é parte de pesquisa que atenta para o peso crescente que a circulação internacional de pessoas, saberes e práticas tem alcançado nos processos de escolarização e formação profissional de determinados setores sociais. Considerando os recursos públicos que a Capes, o CNPq e a Fapesp destinam à formação de pesquisadores com vistas ao fomento à pesquisa e aos investimentos em ciência e tecnologia no horizonte da circulação internacional, recortamos para este artigo a descrição e a análise preliminares da base de dados de bolsistas no exterior dessas agências de fomento, no período de 1970 a 2000. O movimento de fluxos, a partir da metodologia quantitativa de correlação de variáveis, desenha as tendências dos intercâmbios acadêmicos internacionais promovidos pelas três agências e nas diversas áreas do conhecimento, sendo que se procura contextualizá-las nas políticas de desenvolvimento científico-tecnológico desenvolvidas pelo Estado brasileiro no período.

INTERCÂMBIO DE ESTUDANTES - BOLSAS DE ESTUDO - CAPES, CNPq, FAPESP DESENVOLVIMENTO CIENTÍFICO
\end{abstract}

\section{ABSTRACT}

INTERNATIONAL ACADEMIC EXCHANGE PROGRAMS: CAPES, CNPQ AND FAPESP FELLOWSHIPS. This article is part of a study considering the growing importance of the international transit of people, knowledge, and practices in the schooling and professional education processes of some social segments. Considering the public funds made available by the Coordination for the Improvement of Higher Education Personnel - Capes -, the National Council for Scientific and Technological Development - CNPq - and the State of São Paulo Research Foundation Fapesp - to support researchers' fellowships abroad, aming to improve research and investments on Science and Technology on the context of international exchanges, we have dedicated this article to the preliminary description and analysis of the database of fellows funded abroad by

Esta pesquisa contou com financiamento da Coordenação de Aperfeiçoamento de Pessoal de Nível Superior - Capes. 
these research agencies from 1970 to 2000. The movement of flows based on the quantitative methodology of the correlation of variables draws the trends of international academic exchange programs in the three research institutions and in the different areas of knowledge, and we intend to analyse them taking into account the scientific and technological development policies adopted by Brazilian State on the period.

STUDENTS EXCHANGES - SCHOLARSHIPS - CAPES, CNPQ, FAPESP - SCIENTIFIC DEVELOPMENT

No contexto mundial de integração produtiva, comercial e financeira, o significado econômico e geopolítico dos processos de globalização deve ser pensado considerando sua repercussão no campo social, cultural, profissional e pessoal. As economias globais, resultantes do processo de desenvolvimento do modo de produção capitalista, acarretam profundas transformações nas esferas da produção, da circulação e do consumo dos bens materiais e simbólicos, na regulação do trabalho e na configuração das relações sociais.

A reconfiguração do tempo e do espaço que incide no mundo das mercadorias acaba por estimular a circulação de pessoas, saberes e práticas. A sofisticação e a aceleração dos meios de transporte e comunicação, que repercutem nos bens materiais, simbólicos e financeiros, afetam também o intercâmbio de pessoas, saberes e práticas.

É a circulação de pessoas, saberes e práticas que nos interessa. Neste artigo atentamos para os fluxos internacionais dos intercâmbios acadêmicos realizados por bolsistas brasileiros da Coordenação de Aperfeiçoamento de Pessoal de Nível Superior - Capes -, do Conselho Nacional de Desenvolvimento Científico e Tecnológico - CNPq - e da Fundação de Amparo à Pesquisa do Estado de São Paulo - Fapesp -, no período de 1970 a 2000.

\section{REFERENCIAL TEÓRICO}

A porosidade das fronteiras nacionais alcançada pela etapa atual do modo de produção capitalista, tendo em vista a produção, a circulação e o consumo de bens materiais e financeiros, produz efeitos nas esferas não apenas econômica e financeira, mas também nas dimensões social e cultural.

Harvey (2006), em A produção capitalista do espaço, aponta para a sofisticação dos meios de transporte e comunicação que anulam o espaço 
geográfico e o tempo despendido no processo produtivo, possibilitando a maximização dos lucros. Ou seja, quanto menor o tempo de giro de um capital, maior será a mais-valia. Essa anulação do tempo e do espaço que incide sobre as mercadorias termina por estimular outras formas de circulação. Os avanços tecnológicos que recaem sobre os meios de transporte e comunicação repercutem nos processos de bens de troca, nos mercados de capitais e na mobilidade de pessoas, saberes e práticas.

A tendência contemporânea de intensificação do fluxo internacional de bens, serviços, capitais, informações tem ressonância no campo da mobilidade de pessoas e práticas e das ofertas e demandas educacionais. A experiência internacional vem se apresentando como componente importante para a análise dos sistemas nacionais de educação, as estratégias familiares de diferenciação no mercado de diplomas e a formação de setores profissionais.

O caráter estratégico e distintivo dos processos formativos internacionais tem sido alvo de reflexão por parte de vários pesquisadores. Os trabalhos de Dezalay (1992, 1993), Dezalay e Garth (2000), Nogueira, Romanelli e Zago (2000), Almeida e Nogueira (2002) e Almeida et al. (2004) sublinham que a compreensão desses processos formativos exige o estudo dos movimentos de fluxos e dos efeitos dessa circulação nas trajetórias pessoais, escolares, profissionais e institucionais.

A literatura sociológica recente (Brito, 2000, 2004; Jay, 2002; Nogueira, 1998; Pinçon, Pinçon-Charlot, 2000; Prado, 2000) aponta que a internacionalização dos estudos, nos diferentes níveis de ensino, vem se configurando como uma estratégia de construção de fronteiras diferenciais que produzem credenciais distintivas no mundo competitivo do mercado de trabalho e do mercado simbólico dos diplomas. Na medida em que se democratizam o acesso e a permanência em níveis de ensino antes reservados a uma minoria, inflaciona-se o mercado de diplomas, desgastando algumas de suas credenciais distintivas. A lógica competitiva do mercado (de trabalho e de bens simbólicos, tais como o diploma), associada às estratégias de construção de fronteiras entre as classes sociais, grupos e categorias, acaba por produzir um deslocamento na definição de competências e habilidades que possam representar um plus nas trajetórias pessoais, escolares e profissionais.

A universalização de títulos escolares não produz necessariamente igualdade de possibilidades de concorrência dos diferentes grupos, classes e 
setores no mercado de trabalho; mas altera o padrão da desigualdade social, ou seja, desloca as zonas de diferenciação das classes, frações de classe, segmentos profissionais etc. (Marshall, 1967). Neste sentido, entendemos que os intercâmbios internacionais constituem uma problemática contemporânea afeta à Sociologia da Educação.

Bauman (200 I ) sugere que a compreensão do tempo e do espaço contemporâneo engloba a transformação multifacetada dos parâmetros da condição humana. Os processos de globalização da economia e de mundializaçao da cultura, aparentemente homogêneos do ponto de vista da produção capitalista, produzem consequências humanas que ampliam a segregação, a separação e a marginalidade social nas esferas local, nacional e internacional.

Geertz (200I) denomina a cultura e a política da segunda metade do século XX como "um mundo em pedaços", no qual os conceitos de nação, Estado, cultura e política, pensados respectivamente como fronteiras, instituições, comportamentos-crenças e poderes não se aplicam mais. A visão de um mundo definido geográfica e culturalmente como um consenso em torno de elementos fundamentais, tais como concepções, sentimentos e valores comuns, parece pouco viável diante de tamanha dispersão, circulação e desarticulação. Geertz entende que "são as falhas, as dispersões, as mobilidades humanas e as fissuras que parecem demarcar a paisagem da identidade coletiva" (p.219).

Nesse sentido, examinamos os dados quantitativos dos intercâmbios acadêmicos internacionais por meio de bolsas no exterior como a ponta do iceberg de circulação de pessoas, saberes e práticas na modernidade, que a Sociologia da Educação se esforça por compreender. Eles nos interessam também porque participam de políticas públicas endereçadas à educação.

\section{OBJETIVOS E METODOLOGIA}

Pretendemos analisar os movimentos de fluxos de bolsistas brasileiros no exterior, as similitudes e as particularidades das três agências de fomento à pesquisa, tendo em vista as diferentes áreas do conhecimento e as grandes áreas do saber.

Considerando a contribuição que a Capes, o CNPq e a Fapesp ofereceram para o processo de investimento em ciência e tecnologia; para a profissionalização dos cientistas em nível de pós-graduação; para a formação 
de pesquisadores; e para a consolidação de redes internacionais de trocas culturais e acadêmicas, a pesquisa tomou como suporte as listagens de bolsistas no exterior destas três agências. Tentou-se cobrir o período de 1970 a 2000 , dada a importância destas décadas no processo de consolidação das agências de fomento, no volume de recursos públicos destinados à pesquisa, na atuação concomitante dessas agências e no desenvolvimento dos programas de pósgraduação no país segundo padrões internacionais.

Inicialmente foram examinadas as listas nominativas de bolsistas no exterior, fornecidas pelas agências de fomento: Capes, agência ligada ao Ministério da Educação; o CNPq, órgão ligado ao Ministério da Ciência e Tecnologia; e a Fapesp, ligada ao governo do Estado de São Paulo. As listagens se revelaram heterogêneas quanto à natureza dos dados oferecidos e quanto ao período por eles coberto.

Os dados fornecidos pela Capes cobriam o período de 1987 a 2000 e discriminavam: nome completo do bolsista, ano de nascimento, naturalidade, sexo; modalidade da bolsa, instituição de ensino superior - IES - de origem, IES de destino, código de área do projeto de pesquisa, área de formação do pesquisador; mês e ano do início da bolsa, mês e ano do término da bolsa, país de destino, nível de formação do bolsista; título da tese, nome do orientador no exterior para mestrado e doutorado pleno, nome do orientador no Brasil para mestrado e doutorado sanduíche. A listagem da Capes totalizou 6.089 bolsistas no exterior.

O CNPq forneceu dados que cobriam o período de 1986 a 1999 e identificavam: nome completo do bolsista, CPF, data de nascimento, naturalidade, sexo; modalidade da bolsa, IES de origem, IES de destino, área, subárea, especialidade; dia, mês e ano do início da bolsa, dia, mês e ano do término da bolsa, país de destino. A listagem do CNPq inteirou 7.730 bolsistas no exterior.

A Fapesp disponibilizou dados referentes ao período de 1992 a 1999 que apontavam: nome completo do bolsista, data de nascimento, sexo; modalidade da bolsa, IES de origem, IES de destino, área, subárea; dia, mês e ano do início da bolsa, dia, mês e ano do término da bolsa, país de destino; título do projeto de pesquisa. A listagem da Fapesp atestou 2.07I bolsistas no exterior.

Concomitantemente, trabalhamos com um conjunto de textos (Toledo, 2002; lanni, 2000, 2003; Cruz, 1999, 2002; Miyamoto, 1999) que sugeriam que os intercâmbios internacionais deveriam ser pensados numa relação de 
interdependência com o processo de globalização da economia brasileira, as oscilações da política de relações internacionais, as alterações dos governos nacionais e as transformações no campo da produção cultural. Visualizávamos que as décadas de 1970 a 2000 produziram, ao mesmo tempo, uma intensificação das relações econômicas de importação-exportação, um aprofundamento das relações internacionais no eixo Brasil-EUA e uma diversificação das trocas culturais em direções variadas. A modalidade de formação educativa trabalhada encontrava-se na interface dessas questões.

Os dados das diferentes agências foram unificados', compondo um banco de 15.890 bolsistas e as informações codificadas, tendo em vista a produção de gráficos, tabelas, quadros que cruzam variáveis diferentes e que auxiliam na compreensão dos movimentos de fluxos da circulação internacional de bolsistas brasileiros. As variáveis unificadas foram: nome dos bolsistas, ano de nascimento, sexo; agência financiadora, IES de origem, IES de destino, código de área, área; ano de início da bolsa, ano de término da bolsa, país de destino; modalidade de bolsa.

O desenvolvimento da pesquisa evidenciou que os dados quantitativos ofereciam indicadores para a compreensão da circulação internacional de bolsistas brasileiros, suas particularidades e similitudes nas diferentes áreas do conhecimento, nos diferentes países receptores e nas três agências. Vimonos diante de uma pesquisa quantitativa de tipo descritivo e de correlação de variáveis. A pesquisa quantitativa descritiva "estuda as características de um fenômeno" tendo em vista a descrição de seus movimentos, suas regularidades e particularidades. A de correlação de variáveis "controla certo número de variáveis e especifica o grau em que estão relacionadas", considerando o interesse da pesquisa (Campos, 2001 , p. I80). O método quantitativo, ao abranger o universo de bolsistas brasileiros no exterior, oferecia um panorama de fluxo de todas as áreas do conhecimento.

\section{DESCRIÇÃO DOS FLUXOS DE BOLSAS NO EXTERIOR}

I. O trabalho de unificação da base de dados foi realizado entre dez./2002 e jan./2003. Contamos, à época, com a assessoria de Boudeg Salah, estatístico do Centre de Sociologie Européenne, da École des Hautes Études em Sciences Sociales - CSE/EHESS -, de Paris, e de Cristina Vermelho, docente da Pontifícia Universidade Católica de Curitiba - PUC-PR. 
Considerando a distribuição total de bolsas no exterior, segundo os dados fornecidos pelas três agências², obtivemos os dados que se seguem:

\section{Capes}

Ofereceu, no período de 1987 a 2000, um total de 6.089 bolsas no exterior, distribuído entre nove áreas, incluindo todas as modalidades ${ }^{3}$. Dentre elas, cerca de $60 \%$ foram destinadas a bolsistas do sexo masculino ${ }^{4}$.

As áreas mais beneficiadas pela Capes foram: em primeiro lugar, empatadas, as Ciências Humanas e as Ciências Exatas e da Terra; em segundo lugar, as Engenharias e, em terceiro, as Ciências Sociais Aplicadas (Tab. I).

As Ciências Humanas receberam 16,71\% das bolsas no exterior, das quais $57 \%$ destinadas ao sexo feminino. Para as Ciências Exatas e da Terra coube também 16,71\% das bolsas no exterior, com 73\% destinadas a bolsistas do sexo masculino. As Engenharias foram contempladas com 14,79\% das bolsas, destinando cerca de $80 \%$ para o sexo masculino. As Ciências Sociais Aplicadas receberam 13,66\%, sendo cerca de $60 \%$ destinadas a bolsistas do sexo masculino (Tab. I).

2. Segundo tabela Capes, referendada pelas três agências de fomento à pesquisa, os domínios do saber estão divididos em nove áreas que agregam todos os campos disciplinares. São elas: Área I - Ciências Exatas e da Terra: inclui as disciplinas de Matemática, Probabilidade Estatística, Ciência da Computação, Astronomia, Física, Química, Geociências, Oceanografia. Área 2 Ciências Biológicas: inclui todos os ramos da Biologia e Ecologia. Área 3 - Engenharias: inclui todos os ramos das Engenharias. Área 4 - Ciências da Saúde: inclui Medicina, Odontologia, Farmácia, Enfermagem, Saúde Coletiva, Fisioterapia e Terapia Ocupacional, Educação Física. Área 5 - Ciências Agrárias: inclui todos os ramos da Agronomia, Zootecnia, Recursos Pesqueiros e Engenharia de Pesca, Medicina Veterinária, Ciência e Tecnologia de Alimentos. Área 6 - Ciências Sociais Aplicadas: inclui o Direito, Administração, Turismo, Economia, Arquitetura e Urbanismo, Planejamento Regional e Urbano, Demografia, Comunicação e Informação e Publicidade, Serviço Social, Economia Doméstica. Área 7 - Ciências Humanas: inclui Filosofia, Teologia, Sociologia, Antropologia, Arqueologia, História, Geografia, Psicologia, Educação e Ciência Política. Área 8 - Linguística, Letras e Artes: inclui Linguística e Letras, Artes e Música. Área 9-Outros.

3. Incluem-se nas modalidades de bolsa no exterior: Mestrado, Especialização, Doutorado, Sanduíche, Pós-Doutorado, Outros (Congressos, Simpósios, Conferências, Estágios).

4. Operamos com a categoria sexo, masculino e feminino, tal como discriminada nas listagens das três agências. Temos consciência de que ela não corresponde à categoria gênero. Vide Scott (1990). 
TABELA I

DISTRIBUIÇÃO DE BOLSAS NO EXTERIOR SEGUNDO AS AGÊNCIAS DE FOMENTO E AS NOVE ÁREAS

\begin{tabular}{|c|c|c|c|c|c|c|}
\hline \multirow{4}{*}{$\begin{array}{c}\text { Áreas/Agências } \\
\text { । } \\
\text { Exatas e da Terra }\end{array}$} & \multirow{2}{*}{\multicolumn{2}{|c|}{$\begin{array}{l}\text { Capes } \\
1018 \\
16,72 \%\end{array}$}} & \multirow{2}{*}{\multicolumn{2}{|c|}{$\begin{array}{c}\mathrm{CNPq} \\
1928 \\
24,94 \%\end{array}$}} & \multirow{2}{*}{\multicolumn{2}{|c|}{$\begin{array}{c}\text { Fapesp } \\
667\end{array}$}} \\
\hline & & & & & & \\
\hline & $M$ & $F$ & $M$ & $F$ & $M$ & $\mathrm{~F}$ \\
\hline & $\begin{array}{c}736 \\
72,29 \% \\
\end{array}$ & $\begin{array}{c}282 \\
27,70 \% \\
\end{array}$ & $\begin{array}{c}1436 \\
74,48 \% \\
\end{array}$ & $\begin{array}{c}492 \\
25,52 \% \\
\end{array}$ & $\begin{array}{c}423 \\
63,42 \% \\
\end{array}$ & $\begin{array}{c}244 \\
36,58 \% \\
\end{array}$ \\
\hline \multirow{3}{*}{$\begin{array}{c}2 \\
\text { Biológicas }\end{array}$} & \multicolumn{2}{|c|}{$\begin{array}{c}485 \\
7,96 \%\end{array}$} & \multicolumn{2}{|c|}{$\begin{array}{c}87 \mid \\
\mid 1,26 \%\end{array}$} & \multicolumn{2}{|c|}{$\begin{array}{c}394 \\
19,02 \%\end{array}$} \\
\hline & $\bar{M}$ & $F$ & $M$ & $F$ & $M$ & $F$ \\
\hline & $\begin{array}{c}223 \\
46,07 \%\end{array}$ & $\begin{array}{c}265 \\
54,63 \%\end{array}$ & $\begin{array}{c}419 \\
48,11 \%\end{array}$ & $\begin{array}{c}452 \\
51,89 \%\end{array}$ & $\begin{array}{c}226 \\
57,37 \%\end{array}$ & $\begin{array}{c}168 \\
42,64 \%\end{array}$ \\
\hline \multirow{3}{*}{$\begin{array}{c}3 \\
\text { Engenharias }\end{array}$} & \multicolumn{2}{|c|}{$\begin{array}{c}901 \\
14.79 \%\end{array}$} & \multicolumn{2}{|c|}{$\begin{array}{l}1268 \\
16,40 \%\end{array}$} & \multicolumn{2}{|c|}{$\begin{array}{c}216 \\
10,42 \%\end{array}$} \\
\hline & $M$ & $\mathrm{~F}$ & $M$ & $F$ & $M$ & $F$ \\
\hline & $\begin{array}{c}714 \\
79,25 \%\end{array}$ & $\begin{array}{c}187 \\
20,75 \%\end{array}$ & $\begin{array}{c}1051 \\
82,89 \%\end{array}$ & $\begin{array}{c}217 \\
17,11 \%\end{array}$ & $\begin{array}{c}151 \\
69,91 \%\end{array}$ & $\begin{array}{c}65 \\
30,09 \%\end{array}$ \\
\hline \multirow{3}{*}{$\begin{array}{c}4 \\
\text { Ciências da Saúde }\end{array}$} & \multicolumn{2}{|c|}{$\begin{array}{c}67 \mid \\
\mid 1,01 \%\end{array}$} & \multicolumn{2}{|c|}{$\begin{array}{c}958 \\
12,39 \%\end{array}$} & \multicolumn{2}{|c|}{$\begin{array}{c}282 \\
\mid 3,61 \%\end{array}$} \\
\hline & $M$ & $F$ & $M$ & $F$ & $M$ & $F$ \\
\hline & $\begin{array}{c}366 \\
54,71 \% \\
\end{array}$ & $\begin{array}{c}305 \\
45,45 \% \\
\end{array}$ & $\begin{array}{c}548 \\
57,20 \% \\
\end{array}$ & $\begin{array}{c}410 \\
42,80 \% \\
\end{array}$ & $\begin{array}{c}190 \\
67,38 \% \\
\end{array}$ & $\begin{array}{c}92 \\
32,62 \% \\
\end{array}$ \\
\hline \multirow{3}{*}{$\begin{array}{c}5 \\
\text { Ciências Agrárias }\end{array}$} & \multicolumn{2}{|c|}{$\begin{array}{c}411 \\
6,74 \% \\
\end{array}$} & \multicolumn{2}{|c|}{$\begin{array}{c}762 \\
9,85 \% \\
\end{array}$} & \multicolumn{2}{|c|}{$\begin{array}{c}139 \\
6,71 \% \\
\end{array}$} \\
\hline & $M$ & $F$ & $M$ & $F$ & $M$ & $F$ \\
\hline & $\begin{array}{c}298 \\
72,51 \% \\
\end{array}$ & $\begin{array}{c}113 \\
27,49 \% \\
\end{array}$ & $\begin{array}{c}549 \\
72,05 \% \\
\end{array}$ & $\begin{array}{c}213 \\
27,95 \% \\
\end{array}$ & $\begin{array}{c}98 \\
70,50 \% \\
\end{array}$ & $\begin{array}{c}41 \\
29,5 \% \\
\end{array}$ \\
\hline \multirow{3}{*}{$\begin{array}{c}6 \\
\text { Ciências Sociais } \\
\text { Aplicadas }\end{array}$} & \multicolumn{2}{|c|}{$\begin{array}{c}832 \\
13,66 \%\end{array}$} & \multicolumn{2}{|c|}{$\begin{array}{c}737 \\
9,53 \%\end{array}$} & \multicolumn{2}{|c|}{$\begin{array}{c}49 \\
2,36 \%\end{array}$} \\
\hline & $M$ & $F$ & $M$ & $F$ & $M$ & $F$ \\
\hline & $\begin{array}{c}495 \\
59,57 \% \\
\end{array}$ & $\begin{array}{c}337 \\
40,50 \% \\
\end{array}$ & $\begin{array}{c}464 \\
62,96 \% \\
\end{array}$ & $\begin{array}{c}273 \\
37,04 \%\end{array}$ & $\begin{array}{c}34 \\
69,39 \%\end{array}$ & $\begin{array}{c}15 \\
30,61 \% \\
\end{array}$ \\
\hline \multirow{3}{*}{$\begin{array}{c}7 \\
\text { Ciências Humanas }\end{array}$} & \multicolumn{2}{|c|}{$\begin{array}{l}1018 \\
16,71 \% \\
\end{array}$} & \multicolumn{2}{|c|}{$\begin{array}{c}849 \\
10,98 \% \\
\end{array}$} & \multicolumn{2}{|c|}{$\begin{array}{c}226 \\
10,9 \mid \% \\
\end{array}$} \\
\hline & $M$ & $F$ & $M$ & $\mathrm{~F}$ & $M$ & $\mathrm{~F}$ \\
\hline & $\begin{array}{c}444 \\
43,70 \%\end{array}$ & $\begin{array}{c}574 \\
56,38 \%\end{array}$ & $\begin{array}{c}385 \\
45,35 \%\end{array}$ & $\begin{array}{c}464 \\
54,65 \%\end{array}$ & $\begin{array}{c}136 \\
60,18 \%\end{array}$ & $\begin{array}{c}90 \\
39,82 \%\end{array}$ \\
\hline \multirow{3}{*}{$\begin{array}{c}8 \\
\text { Ling., Letras e } \\
\text { Artes }\end{array}$} & & & & & & \\
\hline & $M$ & $F$ & $M$ & $F$ & $M$ & $\mathrm{~F}$ \\
\hline & $\begin{array}{c}336 \\
44,68 \% \\
\end{array}$ & $\begin{array}{c}417 \\
55,37 \% \\
\end{array}$ & $\begin{array}{c}142 \\
39,78 \% \\
\end{array}$ & $\begin{array}{c}215 \\
60,22 \%\end{array}$ & $\begin{array}{c}53 \\
55,21 \% \\
\end{array}$ & $\begin{array}{c}43 \\
44,79 \% \\
\end{array}$ \\
\hline & & & & & & \\
\hline Outros & $M$ & $\mathrm{~F}$ & $M$ & $\mathrm{~F}$ & $M$ & $\mathrm{~F}$ \\
\hline & 0 & 0 & 0 & 0 & $\begin{array}{c}1 \\
50 \%\end{array}$ & $\begin{array}{c}1 \\
50 \% \\
\end{array}$ \\
\hline & & & & & & \\
\hline Total & $M$ & $\mathrm{~F}$ & $M$ & $\mathrm{~F}$ & $M$ & $\mathrm{~F}$ \\
\hline & $\begin{array}{c}3613 \\
59,33 \%\end{array}$ & $\begin{array}{c}2475 \\
40,05 \%\end{array}$ & $\begin{array}{c}4994 \\
64,60 \%\end{array}$ & $\begin{array}{c}2736 \\
35,39 \%\end{array}$ & $\begin{array}{c}1312 \\
63,35 \%\end{array}$ & $\begin{array}{c}759 \\
36,64 \%\end{array}$ \\
\hline
\end{tabular}

Fonte: Capes/CNPq/ Fapesp (dados unificados). 
Reagrupando as nove áreas nos três campos do conhecimento (Ciências Exatas, Humanas e Biológicas), verificamos que a Capes concedeu 42,74\% bolsas no exterior às áreas de Ciências Humanas, Sociais Aplicadas e Letras, Linguística e Artes, distribuídas equitativamente entre sexo masculino e feminino. Em segundo lugar, vieram as áreas das Ciências Exatas e da Terra e as Engenharias, com $31,51 \%$ das bolsas, $76 \%$ das quais para o sexo masculino. Em terceiro lugar, foram atribuídos 27,73\% às áreas das Ciências Biológicas, da Saúde e Agrárias, com 57\% destinadas a bolsistas do sexo masculino (Tab. 2).

TABELA 2

DISTRIBUIÇÃO DE BOLSAS NO EXTERIOR SEGUNDO AS AGÊNCIAS DE FOMENTO E OS CAMPOS DO CONHECIMENTO (EXATAS, BIOLÓGICAS E HUMANAS)

\begin{tabular}{|c|c|c|c|c|c|c|c|c|}
\hline $\begin{array}{c}\text { Campos de } \\
\text { Conhecimento/ } \\
\text { Agências }\end{array}$ & \multicolumn{2}{|c|}{$\begin{array}{c}\text { Capes } \\
\text { Números/ } \\
\text { porcentagem }\end{array}$} & \multicolumn{2}{|c|}{$\begin{array}{c}\text { CNPq } \\
\text { Números/ } \\
\text { porcentagem }\end{array}$} & \multicolumn{2}{|c|}{$\begin{array}{c}\text { Fapesp } \\
\text { Números/ } \\
\text { porcentagem }\end{array}$} & \multicolumn{2}{|c|}{$\begin{array}{c}\text { TOTAL POR } \\
\text { ÁREA } \\
\text { Números/ } \\
\text { porcentagem }\end{array}$} \\
\hline \multirow{4}{*}{$\begin{array}{c}\text { C.EXATAS } \\
\text { (C.Ex/Terra e } \\
\text { Engenharias) }\end{array}$} & \multicolumn{2}{|c|}{$\begin{array}{c}1919 \\
(31,51 \%)\end{array}$} & \multicolumn{2}{|c|}{$\begin{array}{c}3196 \\
41,34 \%\end{array}$} & \multicolumn{2}{|c|}{$\begin{array}{c}883 \\
42,63 \\
\end{array}$} & \multicolumn{2}{|c|}{$\begin{array}{r}5998 \\
37,8 \% \\
\end{array}$} \\
\hline & $M$ & $\mathrm{~F}$ & $M$ & $\mathrm{~F}$ & $M$ & $\mathrm{~F}$ & $M$ & $\mathrm{~F}$ \\
\hline & 1450 & 469 & 2487 & 709 & 574 & 309 & 4511 & 1487 \\
\hline & $75,56 \%$ & $24,43 \%$ & $77,81 \%$ & $22,18 \%$ & $65 \%$ & $34,99 \%$ & $75,22 \%$ & $24,79 \%$ \\
\hline \multirow{4}{*}{$\begin{array}{l}\text { C.BIOLÓGICAS } \\
\text { (C.Biol, C.Saúde e } \\
\text { C. Agrárias) }\end{array}$} & \multicolumn{2}{|c|}{1567} & \multicolumn{2}{|c|}{$\begin{array}{c}2591 \\
33,51 \%\end{array}$} & \multicolumn{2}{|c|}{$\begin{array}{c}815 \\
39,35 \% \\
\end{array}$} & \multicolumn{2}{|c|}{$\begin{array}{c}4973 \\
131,3 \% \\
\end{array}$} \\
\hline & $M$ & $F$ & \multicolumn{2}{|c|}{ 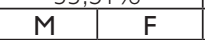 } & \multicolumn{2}{|c|}{ - 15} & \multicolumn{2}{|c|}{\begin{tabular}{l|l}
$M$ & $F$
\end{tabular}} \\
\hline & 887 & 680 & 1516 & 1075 & 514 & 301 & 2917 & 2056 \\
\hline & $56,71 \%$ & $43,39 \%$ & $58,51 \%$ & $41,48 \%$ & $63,06 \%$ & $36,93 \%$ & $58,65 \%$ & $41,34 \%$ \\
\hline \multirow{4}{*}{$\begin{array}{l}\text { C.HUM. SOCIAIS } \\
\text { (C.Hum, C.S..Apl, } \\
\text { Ling. Letras e Artes) }\end{array}$} & \multicolumn{2}{|c|}{$\begin{array}{c}2603 \\
42,74 \% \\
\end{array}$} & \multicolumn{2}{|c|}{$\begin{array}{c}1943 \\
25,13 \% \\
\end{array}$} & \multicolumn{2}{|c|}{$\begin{array}{c}37 \mid \\
17,91 \% \\
\end{array}$} & \multicolumn{2}{|c|}{$\begin{array}{c}4917 \\
130,9 \% \\
\end{array}$} \\
\hline & $M$ & $\mathrm{~F}$ & $M$ & $\mathrm{~F}$ & $M$ & $\mathrm{~F}$ & $M$ & $\mathrm{~F}$ \\
\hline & 1275 & 1328 & 991 & 952 & 223 & 148 & 2489 & 2428 \\
\hline & $49,05 \%$ & $50,95 \%$ & $51 \%$ & $48,99 \%$ & $60,10 \%$ & $39,89 \%$ & $50,62 \%$ & $49,37 \%$ \\
\hline \multirow{4}{*}{$\begin{array}{l}\text { TOTAL POR } \\
\text { AGÊNCIA } \\
\text { Números/ } \\
\text { porcentagem }\end{array}$} & \multicolumn{2}{|c|}{$\begin{array}{c}6089 \\
(100 \%)\end{array}$} & \multicolumn{2}{|c|}{$\begin{array}{l}7730 \\
100 \% \\
\end{array}$} & \multicolumn{2}{|c|}{$\begin{array}{l}2069 \\
100 \%\end{array}$} & \multicolumn{2}{|c|}{$\begin{array}{l}15888 \\
100 \% \\
\end{array}$} \\
\hline & $M$ & $\mathrm{~F}$ & $M$ & $\mathrm{~F}$ & $M$ & $\mathrm{~F}$ & $M$ & $\mathrm{~F}$ \\
\hline & 3612 & 2477 & 4994 & 2736 & 1311 & 758 & 9917 & 597| \\
\hline & $59,32 \%$ & $40,67 \%$ & $64,6 \%$ & $35,39 \%$ & $63,36 \%$ & $36,64 \%$ & $62,41 \%$ & $37,60 \%$ \\
\hline
\end{tabular}

Fonte: Capes/CNPq/ Fapesp (dados unificados).

Os Estados Unidos são o maior receptor de bolsistas brasileiros (29,52\%) da Capes em quase todas as áreas, sendo 64\% do sexo masculino (Tab. 3); as porcentagens apenas perdem para a França nas Ciências Humanas. 
TABELA 3

AGÊNCIAS DE FOMENTO/PRINCIPAIS PAÍSES

RECEPTORES DE BOLSISTAS BRASILEIROS/ÁREAS/SEXO

\begin{tabular}{|c|c|c|c|c|c|c|c|c|c|c|c|c|c|c|c|c|c|c|}
\hline Ag. & \multicolumn{6}{|c|}{ Capes } & \multicolumn{6}{|c|}{ CNPq } & \multicolumn{6}{|c|}{ Fapesp } \\
\hline País & \multicolumn{2}{|c|}{$\mathrm{EU}$} & \multicolumn{2}{|c|}{ FR } & \multicolumn{2}{|c|}{$\overline{G B}$} & \multicolumn{2}{|c|}{ EU } & \multicolumn{2}{|c|}{ FR } & \multicolumn{2}{|c|}{$\mathrm{GB}$} & \multicolumn{2}{|c|}{ EU } & \multicolumn{2}{|c|}{$\mathrm{FR}$} & \multicolumn{2}{|c|}{ GB } \\
\hline $\begin{array}{l}\text { Área/ } \\
\text { Sexo }\end{array}$ & M & $\mathrm{F}$ & $M$ & $\mathrm{~F}$ & $M$ & $\mathrm{~F}$ & M & $\mathrm{F}$ & $M$ & $\mathrm{~F}$ & M & $\mathrm{F}$ & $M$ & $\mathrm{~F}$ & $M$ & $\mathrm{~F}$ & $M$ & $\mathrm{~F}$ \\
\hline I & 217 & 73 & 177 & 72 & 137 & 56 & 576 & 162 & 176 & 87 & 239 & 85 & 175 & 100 & 38 & 24 & 42 & 13 \\
\hline 2 & 104 & 98 & 35 & 45 & 25 & 37 & 206 & 220 & 38 & 59 & 63 & . & 126 & 96 & 20 & 18 & 23 & 16 \\
\hline 3 & 188 & 35 & 140 & 49 & 116 & 29 & 60 & 396 & 116 & 36 & 210 & & 75 & 3 & 17 & 51 & 17 & 12 \\
\hline 4 & 122 & 91 & 62 & 49 & 55 & 59 & 252 & 167 & 51 & 42 & 88 & 79 & 115 & 53 & 5 & 8 & 33 & 8 \\
\hline 5 & 126 & 31 & 51 & 21 & 27 & 11 & 257 & 99 & 43 & 22 & 65 & 26 & 56 & 16 & 8 & 4 & 4 & 5 \\
\hline 6 & 156 & 75 & 106 & 97 & 102 & 78 & 169 & 54 & 75 & 56 & 79 & 60 & 9 & 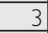 & 7 & 3 & 3 & 0 \\
\hline 7 & 82 & 110 & 144 & 222 & 51 & 72 & 71 & 101 & 117 & 148 & 55 & & 36 & 23 & 38 & 29 & 12 & 10 \\
\hline 8 & 155 & 134 & 54 & 93 & 50 & 85 & 58 & 67 & 31 & 45 & 17 & 39 & 16 & 9 & 19 & 16 & 2 & 7 \\
\hline Tot & 1150 & 647 & 739 & 648 & 563 & 427 & 1649 & 1266 & 647 & 495 & 816 & 462 & 608 & 331 & 152 & 107 & 136 & 66 \\
\hline
\end{tabular}

Fonte: Capes/CNPq/Fapesp (dados unificados).

As áreas que apresentaram maior contingente de bolsistas do sexo masculino foram as Ciências Exatas e da Terra, as Engenharias, as Ciências Agrárias e as Ciências Sociais Aplicadas. Porém nas Ciências Biológicas, da Saúde e em Linguística, Letras e Artes, houve maior equilíbrio na distribuição das bolsas para ambos os sexos. A única área que apresentou um contingente maior de bolsistas do sexo feminino foi a das Ciências Humanas.

A França veio em segundo lugar no acolhimento aos bolsistas brasileiros, em quase todas as áreas. Recebeu 23,23\% deles, por intermédio da Capes, destes, 53\% do sexo masculino. O intercâmbio de bolsistas brasileiros na França foi mais equilibrado entre os sexos, quando comparado com o dos Estados Unidos. As áreas mais masculinas foram as Ciências Exatas e da Terra, Engenharias, Ciências Agrárias e Ciências Sociais Aplicadas. A que apresentou certo equilíbrio foi a das Ciências da Saúde. Predominaram bolsistas do sexo feminino nas Ciências Biológicas, Humanas e Linguística, Letras e Artes.

O terceiro lugar nesse intercâmbio coube à Grã-Bretanha em quase todas as áreas: recebeu 16,25\% dos bolsistas brasileiros da Capes, sendo 57\% do sexo masculino. Os dados apontam maior equilíbrio no acolhimento a bolsistas de ambos os sexos por parte da Grã-Bretanha do que pelos Estados Unidos. As áreas mais masculinas foram Ciências Exatas e da Terra, Engenharias, Ciências Agrárias e Ciências Sociais Aplicadas. A área das Ciências da Saúde apresentou certo equilíbrio, enquanto nas Ciências Biológicas, Humanas e em Linguística, Letras e Artes houve predominância do sexo feminino. 
Apesar de os EUA se apresentarem como o maior receptor de bolsistas da Capes, quando agrupamos os dados de fluxos verificamos que mais de $50 \%$ dos bolsistas dirigiram-se a vários países da Europa. Isto é significativo, considerando que muitos desses bolsistas são professores universitários que exercem influência na formação dos alunos e na constituição de redes de intercâmbios acadêmicos.

A observação do movimento de bolsas da Capes no exterior apontou também que $43 \%$ dos recursos foram destinados às Ciências Humanas, Ciências Sociais Aplicadas e Linguística, Letras e Artes. Dessas bolsas, 51\% foram destinadas ao sexo feminino, no eixo Brasil-Europa, em geral, e BrasilFrança, em particular.

Quanto à vinculação institucional dos bolsistas da Capes no exterior, os dados apontam que, no período analisado, um volume expressivo de recursos se concentrou em três IES públicas de três estados brasileiros - a Universidade de São Paulo, a Universidade Federal do Rio de Janeiro e a Universidade Federal do Rio Grande do Sul. Por serem sigilosos, não temos acesso aos dados de demanda; apenas conhecemos os dados das bolsas efetivamente concedidas, o que não nos permite inferir se essas concessões se referem ao prestígio e à antiguidade destas IES ou a maior número de solicitações por parte delas.

\section{CNPq}

No período de 1986 a 1999, o CNPq apresentou um total de 7.730 bolsas no exterior, distribuídas entre as nove áreas, considerando todas as modalidades. Dentre essas, 65\% foram destinadas a bolsistas do sexo masculino.

As áreas mais atendidas pelo CNPq foram: em primeiro lugar as Ciências Exatas e da Terra, em segundo lugar as Engenharias e, em terceiro, as Ciências da Saúde (Tab. I).

As Ciências Exatas e da Terra receberam 24,94\% das bolsas no exterior, destinando cerca de $75 \%$ a bolsistas do sexo masculino. As Engenharias receberam 16,40\% das bolsas no exterior, com $83 \%$ concedidas ao sexo masculino. Às Ciências da Saúde coube 12,39\% das bolsas, 58\% delas destinadas ao sexo masculino (Tab. I).

Reagrupadas as nove áreas nos três campos do conhecimento (Ciências Exatas, Humanas e Biológicas), verificamos que o CNPq concedeu às Ciências Exatas, no período analisado, $41,34 \%$ das bolsas no exterior, das quais $78 \%$ 
foram atribuídas ao sexo masculino. Em segundo lugar compareceram as Ciências Biológicas, com 33,51\% das bolsas, 59\% destinadas ao sexo masculino. Em terceiro lugar, participaram as Ciências Humanas, com 25, I3\%, com 5 I \% de bolsistas do sexo masculino (Tab. 2).

Quando se observa as direções de fluxos dos bolsistas do CNPq no exterior, constata-se que: 37,7।\% dos intercâmbios acadêmicos realizaramse no eixo Brasil-Estados Unidos, com 57\% bolsistas do sexo masculino. A preponderância norte-americana se manifesta em quase todos os domínios do saber, exceto nas Ciências Humanas, área em que a França aparece como a maior receptora de bolsistas do CNPq.

As áreas do CNPq que apresentaram maior contingente de bolsistas do sexo masculino nos Estados Unidos foram Ciências Exatas e da Terra, Ciências da Saúde, Ciências Agrárias e Ciências Sociais Aplicadas. A área de Ciências Biológicas apresentou uma distribuição equitativa entre os sexos. As áreas que apresentaram maior contingente de bolsistas do sexo feminino foram as Ciências Humanas e Linguística, Letras e Artes.

Em segundo lugar veio a Grã-Bretanha, que acolheu 16,53\% dos bolsistas do CNPq, com 64\% do sexo masculino. As áreas que apresentaram maior contingente de bolsistas do sexo masculino foram as Ciências Exatas e da Terra, as Ciências Biológicas, as Engenharias e as Ciências Agrárias. O maior equilíbrio de bolsas distribuídas entre os sexos ocorreu nas Ciências da Saúde e nas Ciências Sociais Aplicadas. Também aqui o contingente maior de bolsistas do sexo feminino foi atingido pelas Ciências Humanas e por Linguística, Letras e Artes.

Em terceiro lugar, a França acolheu 14,77\% dos bolsistas do CNPq, 57\% do sexo masculino, cujo maior contingente foi registrado pelas Ciências Exatas e da Terra, Engenharias, Ciências Agrárias e Ciências Sociais Aplicadas. A área que apresentou um contingente mais equilibrado de bolsas distribuídas entre os sexos foi a da Saúde, enquanto as Ciências Biológicas, Humanas e Linguística, Letras e Artes apresentaram maior contingente de bolsistas do sexo feminino (Tab. 3).

O exame dos fluxos de bolsas do CNPq apontou que os Estados Unidos acolheram cerca de 38\% dos bolsistas brasileiros. A Grã-Bretanha e a França, juntas, acolheram cerca de 32\%. Os recursos do CNPq se concentraram nas áreas das Ciências Exatas e da Terra e Engenharias, em bolsas nos Estados Unidos, apesar da presença de intercâmbios em vários países da Europa. 
Quanto à vinculação institucional dos bolsistas do CNPq no exterior, os dados são muito semelhantes aos da Capes. Segundo as áreas, no período analisado, os recursos de bolsas no exterior se concentraram em três IES: Universidade de São Paulo, Universidade Federal do Rio de Janeiro e Universidade Federal do Rio Grande do Sul. A novidade foi a Universidade Federal de Viçosa, na área das Ciências Agrárias.

\section{Fapesp}

Essa instituição forneceu, no período de 1992 a 1999, um total de 2.07 | bolsas no exterior, distribuídas entre as várias áreas, nas diversas modalidades, das quais cerca de 64\% foram destinadas a bolsistas do sexo masculino.

As áreas mais beneficiadas pela Fapesp foram: em primeiro lugar as Ciências Exatas e da Terra; em segundo lugar, as Ciências Biológicas e, em terceiro, as Ciências da Saúde (Tab. I).

As Ciências Exatas e da Terra receberam 32,20\% das bolsas no exterior, destinando $64 \%$ a bolsistas do sexo masculino. As Ciências Biológicas receberam 19,02\% bolsas, das quais 58\% foram atribuídas a bolsistas do sexo masculino. As Ciências da Saúde receberam 13,61\% bolsas, destinando 68\% ao sexo masculino (Tab. I).

Reagrupadas as nove áreas nos três campos do conhecimento, no período analisado, as Ciências Exatas foram as mais beneficiadas, recebendo $42,63 \%$ das bolsas no exterior, das quais $65 \%$ destinadas ao sexo masculino. Em segundo lugar, as Ciências Biológicas acumularam 39,35\% das bolsas no exterior, com $63 \%$ destinadas ao sexo masculino. Em terceiro lugar vieram as Ciências Humanas e Sociais, com 17,91\%, destinando-se 60\% a bolsistas do sexo masculino (Tab. 2).

A observação das direções de fluxos dos bolsistas brasileiros da Fapesp no exterior segundo as áreas permite-nos concluir que os Estados Unidos se revelaram como o país que mais recebeu bolsistas, em quase todas as áreas, perdendo para a França nas Ciências Humanas e em Linguística, Letras e Artes. Seguiram para os Estados Unidos 94 I (45,43\%) bolsistas brasileiros, dos quais $65 \%$ eram homens. No fluxo Brasil-Estados Unidos, o maior contingente de bolsistas do sexo masculino se concentrou nas Ciências Exatas e da Terra, Engenharias, Ciências da Saúde, Ciências Agrárias, Ciências Sociais Aplicadas e em 
Linguística, Letras e Artes. As áreas que apresentaram uma distribuição equitativa de bolsas entre os sexos foram as Ciências Biológicas e Humanas. Nenhuma área da Fapesp apresentou predominância de bolsistas do sexo feminino.

Em segundo lugar, mas com uma distância numérica significativa em relação aos Estados Unidos, destacou-se a França, que acolheu 12,36\% dos bolsistas, cerca de $60 \%$ do sexo masculino. No fluxo Brasil-França, um maior contingente de bolsistas homens foi observado nas Ciências Exatas e da Terra, Engenharias, Ciências Agrárias e Ciências Sociais Aplicadas. A distribuição mais equitativa de bolsas entre os sexos ocorreu nas Ciências Biológicas, as Humanas e em Linguística, Letras e Artes. A única área da Fapesp que apresentou predominância de bolsistas do sexo feminino foi a de Ciências da Saúde.

Em terceiro lugar, a Grã-Bretanha acolheu 9,8\% dos bolsistas, sendo $67 \%$ do sexo masculino, cujo maior contingente foi contemplado pelas Ciências Exatas e da Terra, Ciências da Saúde e Ciências Sociais Aplicadas. As áreas que apresentaram uma distribuição mais eqüitativa de bolsas entre os sexos foram Ciências Biológicas, Engenharias, Ciências Humanas, Ciências Agrárias e Linguística, Letras e Artes (Tab. 3).

Os fluxos de bolsas da Fapesp sugerem que os recursos foram atribuídos majoritariamente às Ciências Exatas, no eixo Brasil-Estados Unidos. A França e a Grã-Bretanha, juntas, receberam menos da metade dos bolsistas da Fapesp do que os que intercambiaram com os Estados Unidos. Do ponto de vista do equilíbrio entre os sexos, os dados apontam que a Fapesp, assim como o CNPq, atribuiu 64\% de suas bolsas no exterior a bolsistas do sexo masculino.

Quanto à vinculação institucional dos bolsistas da Fapesp no exterior, lembramos que ela é uma agência de fomento à pesquisa que opera com recursos advindos do Estado de São Paulo e financia bolsistas que se vinculam a IES circunscritas ao estado. As principais instituições beneficiadas foram: a USP, que se destacou como a IES que mais recebeu recursos em todas as áreas do saber, exceto nas Ciências Biológicas, e, a seguir, a Unicamp e a Universidade Estadual Paulista - Unesp.

\section{UM RECORTE TEMPORAL}

Para explorar outras possibilidades relativas aos dados das três agências de fomento, cruzamos algumas variáveis em anos determinados, tendo em 
vista visualizar a evolução dos fluxos de bolsistas no exterior. O recorte foi efetuado entendendo-se que:

...estas datas são significativas de quatro governos que se sucederam no Brasil. [...]. O ano de 1987 corresponde ao terceiro ano do governo José Sarney; 1991 é o segundo ano do Fernando Collor, antes do impeachment; 1995, o último ano de Itamar Franco; e 1998, o último ano do primeiro mandato de Fernando Henrique. (Canedo, 200I, p.632)

Esses anos foram sugeridos e considerados por outras pesquisas que tomaram como suporte os dados de bolsas no exterior da Capes, CNPq e Fapesp ${ }^{5}$.

A intenção é mostrar a distribuição de bolsas segundo as áreas nas duas agências federais, Capes e CNPq, e na agência do Estado de São Paulo, Fapesp. Esta, embora tenha sido agrupada com as agências federais, comparece apenas nos anos de 1995 e 1998, em decorrência das informações disponibilizadas no momento de realização da pesquisa (2002).

Pode-se inferir, com base nos dados das tabelas 4 e 5, que, apesar das oscilações que marcaram o volume e a direção dos fluxos nas diferentes áreas, a Capes conseguiu manter, no período de 1987 a 1998, uma política de incremento de recursos destinados ao envio de bolsistas ao exterior. $\mathrm{O} C \mathrm{NPq}$ apresentou recursos expressivos no período de 1987 a 1991, que diminuíram significativamente em quase todas as áreas nos períodos de 1991 a 1995 e 1995 a 1998. Durante os governos de Fernando Collor e Fernando Henrique Cardoso, essa agência federal não conseguiu manter o mesmo patamar de fomento ao desenvolvimento científico e tecnológico. Os recursos destinados a bolsas no exterior decresceram proporcionalmente. A Fapesp, de 1995 a 1998, elevou seus investimentos em bolsas no exterior em quase todas as áreas; apenas a área de Linguística, Letras e Artes teve recursos diminuídos.

5. Referimo-nos ao Projeto Capes/Comitê Francês de Avaliação da Cooperação Universitária Cofecub - n. 345/0 I, Internacionalização dos Intercâmbios Científicos e Recomposição das Elites Nacionais (1970-2000), coordenado pelos profs. drs. Afrânio Garcia Junior (Centre de Recherches sur le Brésil Contemporain - CRBC/EHESS, Paris) e Letícia Bicalho Canedo (Grupo de Estudos sobre Instituição Escolar e Organizações Familiares/Faculdade de Educação - Focus/FE, Unicamp). 
TABELA 4

DISTRIBUIÇÃO DE BOLSAS NO EXTERIOR SEGUNDO

AS AGÊNCIAS DE FOMENTO, NOS ANOS DE 1987-199|-1995-1998 E AS ÁREAS

\begin{tabular}{c|r|r|r|r|r|r|r|r|r|r}
\hline Ag. & \multicolumn{4}{|c|}{ Capes } & \multicolumn{4}{c|}{ CNPq } & \multicolumn{2}{c}{ Fapesp } \\
\hline Área & 1987 & 1991 & 1995 & 1998 & 1987 & 1991 & 1995 & 1998 & 1995 & 1998 \\
\hline 1 & 43 & 97 & 95 & 101 & 44 & 217 & 113 & 82 & 80 & 147 \\
\hline 2 & 18 & 36 & 43 & 67 & 14 & 121 & 86 & 24 & 35 & 76 \\
\hline 3 & 28 & 77 & 59 & 194 & 38 & 146 & 87 & 56 & 25 & 44 \\
\hline 4 & 21 & 64 & 51 & 78 & 16 & 133 & 54 & 19 & 32 & 51 \\
\hline 5 & 08 & 28 & 36 & 71 & 22 & 100 & 63 & 19 & 20 & 34 \\
\hline 6 & 29 & 69 & 82 & 73 & 24 & 79 & 73 & 22 & 04 & 12 \\
\hline 7 & 44 & 75 & 96 & 124 & 23 & 79 & 81 & 23 & 25 & 44 \\
\hline 8 & 13 & 47 & 72 & 115 & 13 & 36 & 31 & 09 & 23 & 16 \\
\hline 9 & 00 & 00 & 00 & 00 & 00 & 00 & 00 & 00 & 00 & 01 \\
\hline Total & 204 & 493 & 534 & 823 & 194 & 911 & 588 & 254 & 244 & 425 \\
\hline
\end{tabular}

Fonte: Capes/CNPq/Fapesp (dados unificados).

TABELA 5

DISTRIBUIÇÃO DE BOLSAS NO EXTERIOR SEGUNDO AS AGÊNCIAS DE FOMENTO, AS ÁREAS, OS ANOS DE 1987, I991, I995 E 1998 E OS TRÊS PRINCIPAIS PAÍSES RECEPTORES (ESTADOS UNIDOS, FRANÇA E GRÃ-BRETANHA)

\begin{tabular}{|c|c|c|c|c|c|c|c|c|c|c|c|}
\hline \multirow{2}{*}{$\begin{array}{l}\text { Ag. } \\
\text { Área }\end{array}$} & \multirow{2}{*}{$\begin{array}{l}\text { País/ } \\
\text { Ano }\end{array}$} & \multicolumn{4}{|c|}{ CAPES } & \multicolumn{4}{|c|}{ CNPQ } & \multicolumn{2}{|c|}{ FAPESP } \\
\hline & & 1987 & 1991 & 1995 & 1998 & 1987 & 1991 & 1995 & 1998 & 1995 & 1998 \\
\hline \multirow{6}{*}{$\begin{array}{c}\text { I. } \\
\text { C.Ex. } \\
\text { Terra }\end{array}$} & \multirow{2}{*}{ EU } & 8 & 25 & 28 & 29 & 12 & 76 & 57 & 44 & 31 & 63 \\
\hline & & B,60\% & $25,77 \%$ & $29,45 \%$ & $28,71 \%$ & $27,27 \%$ & $35,02 \%$ & $50,44 \%$ & $53,65 \%$ & $38,75 \%$ & $42,85 \%$ \\
\hline & \multirow{2}{*}{$F R$} & 8 & 27 & 2 & 22 & 9 & 32 & 15 & 6 & 9 & 12 \\
\hline & & $18,6 \%$ & $27,83 \%$ & $25,26 \%$ & $21,78 \%$ & $20,45 \%$ & $14,74 \%$ & $13,27 \%$ & $7,31 \%$ & $11,25 \%$ & $8,16 \%$ \\
\hline & \multirow{2}{*}{ B } & 11 & 19 & 17 & 13 & 12 & 35 & 13 & 10 & 6 & 18 \\
\hline & & $58 \%$ & $19,58 \%$ & 17,89\% & $12,87 \%$ & $27,27 \%$ & $16,12 \%$ & $11,5 \%$ & $12,19 \%$ & $7,5 \%$ & 12,24 \\
\hline \multirow{6}{*}{$\begin{array}{c}2 . \\
\text { C. } \\
\text { Biol. }\end{array}$} & \multirow{2}{*}{ EU } & 7 & 12 & 25 & 30 & 2 & 58 & 47 & 12 & 16 & 43 \\
\hline & & $3,88 \%$ & $33,33 \%$ & $58,13 \%$ & $4,77 \%$ & $4,28 \%$ & $47,93 \%$ & $54,65 \%$ & $50 \%$ & $45,71 \%$ & 56,57 \\
\hline & \multirow{2}{*}{ FR } & 3 & 6 & 5 & 9 & 4 & 16 & 11 & 2 & I & 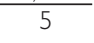 \\
\hline & & $16,66 \%$ & |6,66\% & $11,62 \%$ & $13,43 \%$ & $28,57 \%$ & $13,22 \%$ & $12,79 \%$ & $8,33 \%$ & $2,85 \%$ & $6,57 \%$ \\
\hline & \multirow{2}{*}{$G B$} & 3 & 4 & 7 & 8 & 6 & 13 & 6 & 5 & 6 & 7 \\
\hline & & $16,66 \%$ & $11,11 \%$ & | 6,27\% & |1,94\% & $42,85 \%$ & $10,74 \%$ & $6,97 \%$ & $20,83 \%$ & $17,14 \%$ & $9,21 \%$ \\
\hline & \multirow[b]{2}{*}{} & 8 & 17 & 16 & 43 & 10 & 49 & 31 & 25 & 15 & 2 \\
\hline & & $28,57 \%$ & $22,07 \%$ & $27,11 \%$ & $22,16 \%$ & $26,31 \%$ & $33,56 \%$ & $35,63 \%$ & $44,64 \%$ & $60 \%$ & 54,5 \\
\hline & \multirow{2}{*}{$F R$} & 7 & 15 & 13 & 22 & 2 & 16 & 14 & 6 & I & 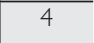 \\
\hline \multirow{3}{*}{ Eng. } & & $25 \%$ & $19,48 \%$ & $22,03 \%$ & $11,34 \%$ & $5,26 \%$ & $10,45 \%$ & $16,09 \%$ & $10,71 \%$ & $4 \%$ & $9,09 \%$ \\
\hline & & 5 & 23 & 12 & 10 & 13 & 34 & 18 & 11 & 2 & 6 \\
\hline & & $7,85 \%$ & $29,87 \%$ & $20,33 \%$ & $5,15 \%$ & $34,21 \%$ & $23,28 \%$ & $20,68 \%$ & $19,64 \%$ & $8 \%$ & $13,63 \%$ \\
\hline
\end{tabular}




\begin{tabular}{|c|c|c|c|c|c|c|c|c|c|c|c|}
\hline \multirow{2}{*}{$\begin{array}{l}\text { Ag. } \\
\text { Área }\end{array}$} & \multirow{2}{*}{$\begin{array}{l}\text { País/ } \\
\text { Ano }\end{array}$} & \multicolumn{4}{|c|}{ CAPES } & \multicolumn{4}{|c|}{ CNPQ } & \multicolumn{2}{|c|}{ FAPESP } \\
\hline & & 1987 & 1991 & 1995 & 1998 & 1987 & |99| & 1995 & 1998 & 1995 & 1998 \\
\hline \multirow{2}{*}{4.} & \multirow{2}{*}{ EU } & 6 & 14 & 12 & 34 & 8 & 58 & 28 & 13 & 17 & 29 \\
\hline & & $28,57 \%$ & $21,87 \%$ & $23,52 \%$ & $43,58 \%$ & $50 \%$ & $43,60 \%$ & $51,85 \%$ & $68,42 \%$ & $53,12 \%$ & $56,86 \%$ \\
\hline \multirow{2}{*}{ C. da } & \multirow{2}{*}{$F R$} & 0 & 15 & 7 & 5 & 1 & 17 & 7 & 2 & 3 & 4 \\
\hline & & $0 \%$ & $23,43 \%$ & I3,72\% & $6,41 \%$ & $6,25 \%$ & $12,78 \%$ & $12,96 \%$ & $10,52 \%$ & $9,37 \%$ & $7,84 \%$ \\
\hline \multirow{2}{*}{ Saúde } & \multirow{2}{*}{ GB } & 6 & 14 & 9 & 18 & 3 & 26 & 7 & 1 & 6 & 7 \\
\hline & & $28,57 \%$ & $21,87 \%$ & $17,64 \%$ & $23,07 \%$ & $18,75 \%$ & $19,54 \%$ & $12,96 \%$ & $5,26 \%$ & | $8,75 \%$ & $13,72 \%$ \\
\hline \multirow{6}{*}{$\begin{array}{c}5 . \\
\text { C. } \\
\text { Agrá. }\end{array}$} & \multirow{2}{*}{ EU } & 2 & 7 & 15 & 30 & 11 & 47 & 38 & 14 & 9 & 20 \\
\hline & & $25 \%$ & $25 \%$ & $41,66 \%$ & $42,25 \%$ & $50 \%$ & $47 \%$ & $60,31 \%$ & $73,68 \%$ & $45 \%$ & $58,82 \%$ \\
\hline & \multirow{2}{*}{ FR } & 5 & 7 & 4 & 7 & 3 & 8 & 10 & 1 & 0 & 3 \\
\hline & & $62,5 \%$ & $25 \%$ & $11,11 \%$ & $9,85 \%$ & $13,63 \%$ & $8 \%$ & $15,87 \%$ & $5,26 \%$ & $0 \%$ & $8,82 \%$ \\
\hline & \multirow{2}{*}{ GB } & 0 & 2 & 6 & 5 & 3 & 11 & 1 & 2 & 0 & 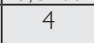 \\
\hline & & О\% & $7,14 \%$ & 16,66 & $7,04 \%$ & $13,63 \%$ & $11 \%$ & ।,58\% & $10,52 \%$ & $0 \%$ & $11,76 \%$ \\
\hline \multirow{2}{*}{6.} & & 6 & 19 & 20 & 25 & 4 & 24 & 36 & 12 & 2 & 1 \\
\hline & & $20,68 \%$ & $27,53 \%$ & $24,39 \%$ & $34,24 \%$ & $16,66 \%$ & $30,37 \%$ & $49,31 \%$ & $54,54 \%$ & $50 \%$ & $8,33 \%$ \\
\hline \multirow{4}{*}{$\begin{array}{c}\text { C. Soc. } \\
\text { Aplic. }\end{array}$} & \multirow[b]{2}{*}{ FR } & 4 & 24 & 20 & 17 & 8 & 21 & 7 & 3 & 0 & 2 \\
\hline & & $13,76 \%$ & $34,78 \%$ & $24,39 \%$ & $23,28 \%$ & $33,33 \%$ & $26,58 \%$ & $9,58 \%$ & $13,63 \%$ & $0 \%$ & $16,66 \%$ \\
\hline & \multirow{2}{*}{ GB } & 9 & 11 & 22 & 12 & 5 & 18 & 8 & I & 0 & 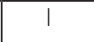 \\
\hline & & $31,03 \%$ & $15,94 \%$ & $26,82 \%$ & $16,43 \%$ & $20,83 \%$ & $22,78 \%$ & $10,95 \%$ & $4,54 \%$ & $0 \%$ & $8,33 \%$ \\
\hline & \multirow{2}{*}{ EU } & 5 & 13 & 20 & 20 & 5 & 18 & 23 & 5 & 5 & 12 \\
\hline & & $17,85 \%$ & $17,33 \%$ & $20,83 \%$ & $16,12 \%$ & $21,73 \%$ & $22,78 \%$ & $28,39 \%$ & $21,73 \%$ & $20 \%$ & $27,27 \%$ \\
\hline \multirow{4}{*}{$\begin{array}{c}\text { C. } \\
\text { Hum. }\end{array}$} & \multirow{2}{*}{ FR } & 10 & 27 & 43 & 36 & 7 & 22 & 25 & 4 & 5 & 7 \\
\hline & & $35,71 \%$ & $36 \%$ & $44,79 \%$ & $29,3 \%$ & $30,43 \%$ & $27,84 \%$ & $30,86 \%$ & $17,39 \%$ & $20 \%$ & $15,9 \%$ \\
\hline & \multirow{2}{*}{ GB } & 2 & 8 & 6 & 19 & 8 & 14 & 11 & 5 & 2 & 8 \\
\hline & & $7,14 \%$ & $10,66 \%$ & $6,25 \%$ & $15,32 \%$ & $34,78 \%$ & $17,72 \%$ & $11,58 \%$ & $21,73 \%$ & $8 \%$ & $18,18 \%$ \\
\hline \multirow{2}{*}{8} & \multirow{2}{*}{ EU } & 9 & 15 & 26 & 34 & 3 & 9 & 10 & 6 & 6 & 6 \\
\hline & & $69,23 \%$ & $31,91 \%$ & $36,11 \%$ & $29,56 \%$ & $23,7 \%$ & $25 \%$ & $32,25 \%$ & $66,66 \%$ & $26,8 \%$ & $37,5 \%$ \\
\hline & $F$ & 1 & 12 & 20 & 22 & 3 & 9 & 9 & 1 & 11 & 7 \\
\hline L.Art. & אודו & $7,69 \%$ & $25,53 \%$ & $27,77 \%$ & $19,13 \%$ & $23,07 \%$ & $25 \%$ & $29,03 \%$ & $11,11 \%$ & $47,82 \%$ & $43,75 \%$ \\
\hline & $G$ & I & 5 & 6 & 29 & 2 & 12 & 5 & 0 & 0 & 0 \\
\hline & 0 & $7,69 \%$ & $10,63 \%$ & $8,33 \%$ & $25,21 \%$ & $15,38 \%$ & $33,33 \%$ & $16,12 \%$ & $0 \%$ & $0 \%$ & $0 \%$ \\
\hline
\end{tabular}

Fonte: Capes/CNPq/ Fapesp (dados unificados).

Como tendência dominante, pode-se sugerir que o fluxo de bolsas para os Estados Unidos, nas diferentes áreas, nas três agências, apresentou elevação. $\bigcirc$ fluxo para a França apresentou um declínio oscilante na maioria das áreas, nas três agências, mas sustentou índices significativos nas Ciências Sociais Aplicadas; Ciências Humanas e Linguística, Letras e Artes, nas quais as trocas com esse país se apresentaram como dominantes. $\bigcirc$ fluxo de bolsas para a Grã-Bretanha, se manteve nas Ciências Exatas e da Terra, Engenharias, Ciências Agrárias, Ciências Sociais Aplicadas e Ciências Humanas. Porém é 
visível o predomínio crescente do fluxo Brasil-Estados Unidos em todas as áreas e nas três agências de fomento.

\section{CONSIDERAÇÕES FINAIS}

A consciência de que a ciência e a tecnologia são componentes importantes da soberania nacional veio a desenvolver-se depois da Segunda Grande Guerra Mundial, com a explosão da bomba atômica. A atividade científica, até então, era essencialmente cultural, não se pensava na pesquisa científica, no Brasil e na maior parte dos países, como instrumento por excelência para se atingir o poder, a riqueza e o desenvolvimento. A bomba atômica adveio de um conhecimento considerado, na época, como essencialmente básico, pesquisa pura. Embora pudessem ser encontrados vários exemplos da pesquisa científica, do conhecimento sistemático e da tecnologia para o desenvolvimento de um país, não havia uma conotação explícita do conhecimento científico-tecnológico como um conhecimento estratégico do ponto de vista político (Moreira, 1979).

impacto da bomba atômica alertou as elites brasileiras para a necessidade de se investir em ciência e tecnologia. A política de modernização do país concebida na era Vargas baseava-se na substituição de importações e prescindia da pesquisa científica e tecnológica que, na época, era realizada por "um seleto e restrito grupo de cientistas concentrado em São Paulo e no Rio de Janeiro" (História dos 50 anos..., 2002, p.24).

A internacionalização da problemática ligada à pesquisa atômica influenciou a criação do Conselho Nacional de Pesquisas - CNPq -, em 1951, que possibilitou uma nova atuação relativa à pesquisa científica. A Lei n. I . 3 | 0 , de I 5 de janeiro de 1951, instituiu o CNPq, subordinado ao Presidente da República, com objetivos explícitos de "apoiar as atividades de pesquisa científica no Brasil" e "incentivar, em cooperação com os órgãos técnicos oficiais, a pesquisa e a prospecção das reservas existentes no país de material apropriado ao aproveitamento da energia atômica" (História dos 50 anos..., 2002, p.25). A preocupação inicial com a energia nuclear foi uma das principais motivações do governo e do primeiro presidente do CNPq, o almirante Álvaro Alberto da Mota e Silva 6 .

6. Almirante Álvaro Alberto (1889-1976), carioca, graduou-se em Engenharia pela Escola Politécnica (RJ), estudou Física na École Centrale Techinique (Bruxelas), atuou na área da energia nuclear. Idealizador e primeiro presidente do CNPq, representou o Brasil junto à Comissão 
As atividades básicas do CNPq ligavam-se ao fomento, à execução de pesquisa e à informação e difusão da ciência e da tecnologia. A atividade de fomento destinava-se à formação de recursos humanos e ao desenvolvimento de pesquisas puras e aplicadas, mediante auxílio financeiro a centros de pesquisas e concessão de bolsas a pesquisadores e estudantes de pós-graduação.

Na criação do CNPq havia o propósito de utilizar um modelo de apoio à pesquisa que contasse com a participação de segmentos da sociedade tais como a indústria. O Conselho priorizava as chamadas "ciências duras", tinha como um de seus principais objetivos fomentar o desenvolvimento científico e tecnológico e contribuir na formulação de políticas nacionais de ciência e tecnologia. $\mathrm{O}$ CNPq se esforçou por criar uma política nuclear para o país, mas se consolidou como uma agência destinada a distribuir recursos a cientistas das ciências biológicas, físicas e das ciências naturais. A atuação do CNPq possibilitou que cientistas brasileiros levassem em frente trabalhos de pesquisa, mesmo quando suas instituições não proporcionavam maiores condições, e alimentou um programa de bolsas de estudo no exterior.

Ao priorizar a ciência e a tecnologia vinculadas à política nuclear, a agência vincou seus intercâmbios no eixo Brasil-Estados Unidos e destinou seus recursos prioritariamente a bolsistas homens que atuavam nas áreas das Ciências Exatas, da Terra e nas Engenharias.

Ainda em 1951, criou-se a Coordenação e Aperfeiçoamento de Pessoal de Nível Superior - Capes -, vinculada ao Ministério da Educação, resultante de uma política deliberada do Estado cujo intuito era disciplinar e orientar o ensino superior no Brasil, tendo em vista a elaboração de uma política de pós-graduação. Idealizada por um grupo no qual se destacava Anísio Teixeira ${ }^{7}$, nasceu da percepção de que a qualificação do ensino superior, com a criação de condições estruturais de formação de pessoal, seria fundamental para o desenvolvimento do país. Três fatores contribuíram para o desenvolvimento da Capes:

de Energia Atômica - CEA - das Nações Unidas - ONU -, assumindo posições contrárias a que os EUA monopolizassem a tecnologia e as matérias-primas nucleares no mundo ocidental.

7. Anísio Teixeira (1922-1971), baiano, graduou-se em Ciências Jurídicas e Sociais no Rio de Janeiro, estudou em Columbia (NY) com o pedagogo John Dewey e atuou no campo das políticas públicas educacionais em nível municipal (BA), estadual (BA e RJ) e federal na Universidade de Brasília - UNB -, na Capes e no Instituto Nacional de Estudos e Pesquisas Educacionais - Inep (Brasília). 
... inserção, na Constituição de 1946, da exigência de que o governo federal destinasse 10\% de seu orçamento à educação; - um forte movimento dos intelectuais brasileiros por melhorias no ensino, que se tornaria conhecido por Escola Nova; - a importância da ciência e tecnologia durante a II Guerra Mundial, que chamou a atenção do governo Vargas para a necessidade de aperfeiçoar o ensino superior para formação de engenheiros, cientistas e pesquisadores. (Motoyama, 200 I, p.2I)

A ideia era distanciar o ensino superior da tendência tradicional de escolas de formação e transformá-lo lentamente em centro de pesquisa que abrigasse uma visão de ciência e de atividade científica. Era preciso investir recursos na formação de profissionais qualificados, tendo em vista que o conhecimento, quando aplicado, reverteria em riquezas nos processos de desenvolvimento e modernização. Em 1965, com a constituição de um sistema nacional de pósgraduação, a Capes iniciou um processo de modernização da universidade, objetivando formar professorado competente para atender à expansão quantitativa, garantindo a elevação dos níveis de qualidade; estimular o desenvolvimento da pesquisa científica por meio da preparação adequada de pesquisadores; assegurar o treinamento eficaz de técnicos e trabalhadores intelectuais do mais alto padrão para fazer face às necessidades do desenvolvimento nacional em todos os setores (Durham, 1986, p.42). A Capes, ao se vincular à educação e à formação docente para o ensino superior, estabeleceu seus intercâmbios no eixo Brasil-Europa e destinou mais de 50\% de bolsas no exterior a mulheres que atuavam nas áreas das Ciências Humanas, Ciências Sociais Aplicadas e Linguística, Letras e Artes.

Até a institucionalização de uma política científica conduzida pelo governo federal, por intermédio da Capes e do CNPq, os financiamentos à pesquisa eram escassos e dependiam muito do prestígio pessoal dos cientistas. $\bigcirc$ Rio de Janeiro, capital da República, que abrigava a sede dos órgãos de fomento, beneficiava-se da condição geográfica e concentrava boa parte da aplicação dos recursos.

Por meio dessas instituições a comunidade científica brasileira pôde investir na construção de uma política governamental de pesquisa, conectada à dinâmica internacional de produção científica e tecnológica. No período de 195I a 1979, receberam bolsas da Capes e do CNPq 879 brasileiros, para 
efetuar estudos e pesquisas nos principais centros científicos do mundo. Entre 1970 e 1998, essas bolsas beneficiaram cerca de 17 mil pesquisadores. Sem uma política pública de pesquisa conduzida pelo Estado dificilmente se alcançaria essa taxa, em razão das crises econômicas e políticas pelas quais o Brasil passou nessas décadas (Canedo, Garcia Jr., 2004/2005, p.29).

O cenário internacional e as relações de interdependência entre nações, que giravam em torno de interesses políticos, econômicos, militares e científicos, consolidaram as instituições de financiamento à pesquisa mantidas pelo Estado, aceleraram a formulação de uma agenda de pesquisa e impulsionaram a formação da comunidade científica que intercambiava com programas e instituições para além das fronteiras nacionais.

Em 1962, fortalecendo a cultura de práticas científicas atreladas a processos de desenvolvimento e modernização, criou-se a Fundação de Amparo à Pesquisa do Estado de São Paulo - Fapesp -, tendo como preocupação dotar o Estado de São Paulo de instrumentos capazes de dar um apoio direto ao financiamento de pesquisas e à concessão de bolsa de estudos. A criação da Fapesp vinha sendo proposta desde 1947, tendo em vista alavancar a industrialização do estado (Almeida, 2000).

A Fapesp nasceu com o propósito de ser uma instituição voltada ao apoio à pesquisa científica. A movimentação foi ampla e contou com a participação de professores das faculdades de Medicina, Filosofia, Economia (Motoyama, 1999). Dois aspectos foram marcantes na criação da Fapesp: a ideia de que a pesquisa deveria ser definida pelos próprios pesquisadores e a inclusão das Ciências Humanas na pauta da fundação e dos financiamentos de pesquisa.

Segundo Cruz, do documento "Ciência e Pesquisa-Contribuição de Homens do Laboratório e da Cátedra", encaminhado em 1947 à Assembleia Constituinte de São Paulo, propondo a criação da Fapesp, consta:

A ciência está destinada a desempenhar um papel cada vez mais preponderante na produção industrial. e as nações que deixarem de entender essa lição hão inevitavelmente de ser relegadas à posição de nações escravas: cortadoras de lenha e carregadoras de água para os povos esclarecidos. (2002, p.4)

Os "paulistas tinham pressa" de ocupar a liderança econômica do país por meio de um esforço planejado do estado, investindo em projetos estratégicos 
para o desenvolvimento e a modernização industrial (Schwartzman, 1979, p. 199-200). Com a Fapesp,

.... Universidade deixou de ser um clube onde se reuniam ilustres médicos, engenheiros e advogados para trocar ideias, que a indústria e a agricultura paulistas encontram apoio e a base para um desenvolvimento tecnológico auto-sustentável, que a Economia, as Ciências Humanas e as Letras foram reconhecidas como atividades válidas e úteis, que, enfim, a pesquisa nas Ciências, nas Técnicas e nas Atividades Culturais fora reconhecida como elemento-chave do progresso da sociedade. Dizer isso hoje é fácil. [...] Pensar isso nos anos 50, 60, na Vila Clementino ou no Bom Retiro, era privilégio de algumas raras cabeças. (Silva, 2002, p.32)

A Fapesp ao se dedicar ao desenvolvimento tecnológico autossustentável, vincou seus intercâmbios no eixo Brasil-Estados Unidos, destinou as bolsas no exterior majoritamente a homens que atuavam nas áreas das Ciências Exatas e Biológicas.

A existência desse sistema institucionalizado de financiamento à pesquisa possibilitou que os cientistas se organizassem como comunidade relativamente autônoma, não dependendo apenas de recursos pessoais ou relacionais para o desenvolvimento de projetos; além disso, a própria visão de ciência foi modificada.

Capes, CNPq e Fapesp passaram a funcionar de modo coordenado a partir da segunda metade da década de sessenta (Schwartzman, 1979, p.247). A existência dessas agências marcou a passagem de iniciativas científicas isoladas, para a formulação de políticas públicas de produção científica. Esse período marcou a consolidação, por parte do Estado brasileiro, de um modelo institucional de apoio à pesquisa aliado ao desenvolvimento da pós-graduação. Com esse modelo o Brasil tem-se esforçado para manter uma tradição de produção científica que agrega interesses de áreas produtoras de conhecimento à criação de agências de fomento e alimenta a interlocução do nacional com o supranacional.

No período Pós-Guerra, os Estados Unidos exerceram supremacia no campo tecnológico-industrial e particularmente no setor da energia nuclear. $\bigcirc$ Brasil, apesar de alinhado à política norte-americana, tentou criar condições 
de desenvolvimento de uma política científica e tecnológica autônoma. Essa foi a principal motivação para a criação do CNPq em 195।. Este órgão tentou pautar sua política no princípio da autonomia, apesar da forte presença próamericana nos meios científicos e governamentais.

A viabilização dessa política demandava profissionais altamente especializados e inseridos nas regras supranacionais de trabalho científico, daí o papel da Capes, investindo no aperfeiçoamento do pessoal de nível superior e criando um programa de bolsas no exterior que assegurava uma política de intercâmbios acadêmicos. As atividades no exterior se tornaram imperativas diante da necessidade de qualificar os projetos de pesquisas desenvolvidos no país. A Fapesp concentrou-se no Estado de São Paulo, direcionando recursos à ciência aplicada e à produção urbano-industrial.

Foi na configuração internacional do Pós-Guerra que a comunidade científica brasileira se organizou e que Capes, CNPq e Fapesp se institucionalizaram e passaram a desenvolver políticas científicas e tecnológicas em cooperação. As três agências dedicaram parte de seus recursos a bolsas no exterior e, como os números evidenciaram, os intercâmbios acadêmicos brasileiros circunscreveram-se, preferencialmente aos Estados Unidos, à França e à Grã-Bretanha.

A política de distribuição de bolsas no exterior sustentada por essas agências permitiu que os intercâmbios acadêmicos internacionais brasileiros não ficassem restritos à circulação de elites: eles se inseriram no campo das políticas públicas de educação e na formação de quadros para a ciência e a tecnologia.

Os dados sobre bolsas no exterior outorgadas pela Capes, pelo CNPq e pela Fapesp dão visibilidade a certa modalidade de intercâmbios acadêmicos internacionais ocorridos nas últimas décadas. A história das agências de fomento, seus objetivos prioritários de pesquisa e suas parcerias institucionais apresentaram-se como elementos explicativos dos vetores dos fluxos.

As bolsas no exterior para as áreas de Ciências Humanas, Ciências Sociais Aplicadas e Linguística, Letras e Artes vieram majoritariamente da Capes, vincularam-se ao esforço de capacitação do ensino superior e seu fluxo dominante desenhou-se no eixo Brasil-Europa. Essa tendência pode-se justificar em razão da influência que o modelo europeu exerceu em alguns domínios da pesquisa no Brasil e, em particular, na concepção de universidade assentada no ensino e na pesquisa. 
Nas áreas das Ciências Exatas, da Terra e Engenharias, bem como nas Ciências Biológicas, Ciências da Saúde e Ciências Agrárias, a influência maior foi a do conhecimento aplicado à produção urbano-industrial e ao desenvolvimento tecnológico, o que explica a tendência de investimentos da Fapesp.

Os intercâmbios internacionais realizados pelos bolsistas brasileiros no período analisado inserem-se no cenário de interdependência dos acordos firmados entre as principais nações mundiais. Eles sinalizam interesses vinculados à pesquisa bélica, a um alinhamento aos interesses hegemônicos norteamericanos e a um redirecionamento da tradição de formação propedêutica europeia que marcou fortemente a sociedade brasileira até a primeira metade do século $X X$.

Os indicativos trazidos pelas fontes de base quantitativa apresentam-se como ponto de partida, com base nos quais devemos perseguir os efeitos destas migrações temporárias nas trajetórias pessoais, escolares e profissionais dos sujeitos envolvidos, o que comporia uma pesquisa de caráter qualitativo.

Para a Sociologia da Educação é importante acompanhar sujeitos que participaram desse tipo de experiência, considerando: o peso crescente que o processo de circulação de pessoas, saberes e práticas vem alcançando na sociedade contemporânea, motivado pelas formas de regulação da produção capitalista; a contribuição que esse processo formador tem trazido para determinados grupos profissionais e as inovações culturais decorrentes dessa forma de investimento de recursos públicos em educação.

\section{REFERÊNCIAS BIBLIOGRÁFICAS}

ALMEIDA, A. M. L' État et les échanges scientifiques internationaux: notes sur le Fapesp à São Paulo. In: COLLOQUE BRÉSIL. Actes.. Paris: CRBC- ÉHESS, 2000. p. I - 15.

ALMEIDA, A. M.; NOGUEIRA, M. A. A Escolarização das elites: um panorama internacional da pesquisa. Petrópolis: Vozes, 2002.

ALMEIDA. M. et al. Circulação internacional e formação intelectual das elites brasileiras. Campinas: Ed. Unicamp, 2004.

BAUMAN, Z. La Globalización: conseqüências humanas. México: Fondo de Cultura Económica, 200 I. 
BRITO, A. X. Habitus de herdeiro, habitus escolar: os sentidos da internacionalização nas trajetórias dos estudantes brasileiros no exterior. In: ALMEIDA. M. et al. Circulação internacional e formação intelectual das elites brasileiras. Campinas: Ed. Unicamp, 2004. p.85- 104. Transformações institucionais e características sociais dos estudantes brasileiros na França. BIB, n. 50, p. |45-62, 2000.

CAMPOS, M. C. S. de S. A Montagem de um projeto de pesquisa. In: LANG, A. B.da S.G. Desafios da pesquisa em Ciências Sociais. São Paulo: FFLCH, 200 I. p. I7I - 189. (Col. Textos, Série 2, 8)

CANEDO, L. B. Masculin, féminin et études universitaires à l'etranger: les boursiers brésiliens de 1987 à 1998. Information sur les Sciences Sociales, Paris, v.40, n.4, p.627-648, 2001.

CANEDO, L. B.; GARCIAJr., A. Les Boursiers brésiliens et l'accès aux formations d'excellence internationales. Cahier du Brésil Contemporain, n.57/60, p.21-48, 2004/2005.

CRUZ, C. H. de B. Apoio na busca pelo conhecimento. Revista Fapesp, n.esp.: Fapesp 40 anos, p.4, jun.2002.

CRUZ, S. C. V. e. Desencontros: o Brasil e o mundo no limiar dos anos 80 (primeira versão). Campinas, Unicamp, nov. I 999. (IFCH-Unicamp, 88)

Organizações internacionais e reformas neoliberais: reflexões a partir do tema da propriedade intelectual (primeira versão). Campinas: Unicamp, ago. 2002. (IFCHUnicamp, 108)

DEZALAY, Y. Marchands de droit. Paris: Fayard, 1992.

Multinationale de l'expertise et dépérissement de l'État. Actes de la recherche en Sciences Sociales, n. 96/97, p.2-30, mars, 1993.

DEZALAY, Y.; GARTH, B. A Dolarização do conhecimento técnico profissional e do Estado: processos transnacionais e questões de legitimidade na transformação do Estado, 1960-2000. Revista Brasileira de Ciências Sociais, v. I5, n.43, p. I63-176, jun.2000.

DURHAM, E. A Política de pós-graduação e as Ciências Sociais. BIB, n. 21, p.4I-55, I sem. 1986.

GEERTZ, C. A Nova luz sobre a Antropologia. Rio de Janeiro: Jorge Zahar, 200 I .

HARVEY, D. A Produção capitalista do espaço. São Paulo: Annablume, 2006.

HISTÓRIA DOS 50 ANOS DO CNPq. Revista Pesquisa Fapesp, n.79, p.24-25, set. 2002.

IANNI, O. Enigmas da modernidade-mundo. Rio de Janeiro: Civilização Brasileira, 2003. 
Teorias da globalização. Rio de Janeiro: Civilização Brasileira, 2000.

JAY, E. As Escolas de grande burguesia: o caso da Suíça. In: ALMEIDA, A. M.; NOGUEIRA, M. A. (orgs.) A Escolarização das elites: um panorama internacional da pesquisa. Petrópolis: Vozes, 2002. p. I20-134.

MARSHALL, T. H. Cidadania, classe social e status. Rio de Janeiro: Zahar, 1967.

MIYAMOTO. S. Perspectivas do estudo das relações internacionais no Brasil: primeira versão. Campinas, Unicamp, fev. 1999. (IFCH-Unicamp, 80)

MOREIRA, M. F. Entrevista In: SCHWARTZMAN, S. Formação da comunidade científica no Brasil. São Paulo: Nacional; Rio de Janeiro: Financiadora de Estudos e Projetos, 1979. p.24I -242.

MOTOYAMA, S. (org.) Educação e democracia. Revista Pesquisa Fapesp, n.3, 2 I -22, jul.200 I (Supl. esp.: Infra-estrutura)

(org.) Fapesp: uma história de política científica e tecnológica, I/2. São Paulo: Edições Fapesp, 1999.

NOGUEIRA, M. A. Estratégias de escolarização em famílias de empresários. In: ALMEIDA, A. M.; NOGUEIRA, M. A. (orgs.) A Escolarização das elites: um panorama internacional da pesquisa. Petrópolis: Vozes, 2002. p.49-65.

Uma dose de Europa ou Estados Unidos para cada filho: estratégias familiares de internacionalização dos estudos. Pro-posições, v.9, n. I (25), p. I I3-3 I, mar. 1998.

NOGUEIRA, M. A.; ROMANELLI, G.; ZAGO, N. (orgs.) Família e escola: trajetórias de escolarização em camadas médias e populares. Petrópolis: Vozes, 2000.

PINÇON, M.; PINÇON-CHARLOT, M. Sociologie de la bourgeoisie. Paris: La Découverte, 2000.

PRADO, C. Em busca do primeiro mundo: intercâmbios culturais como estratégias educativas familiares. In: NOGUEIRA, A. M.; ROMANELLI, G.; ZAGO, N. (orgs.) Família e escola: trajetórias de escolarização em camadas médias e populares. Petrópolis: Vozes, 2000. p. 1 55- 170.

SCOTT, J. Gênero: uma categoria útil de análise histórica. Educação e Realidade, Porto Alegre, v. 16, n.2, p.5-22, 1990.

SCHWARTZMAN, S. Formação da comunidade científica no Brasil. São Paulo: Nacional; Rio de Janeiro: Financiadora de Estudos e Projetos, 1979.

SILVA, L. H. P. da. A Revolução paulista. Revista Pesquisa Fapesp, n.esp.: Fapesp 40 anos, p.32-37, jun.2002. 
Intercâmbios acadêmicos internacionais...

TOLEDO, C. N. de. Universidade, intelectuais e pensamento crítico: primeira versão. Campinas: Unicamp, abr. 2002. (IFCH-Unicamp, 104)

Recebido em: dezembro 2006

Aprovado para publicação em: março 2008 